\title{
An Unusual Cause of Upper Gastrointestinal Tract Obstruction
}

\author{
Karamollah Toolabi ${ }^{1}$, Abbas Zamanian ${ }^{1,2}$, Reza Parsaei ${ }^{1, *}$, Fezzeh Elyasinia ${ }^{1}$
}

1. Department of surgery, Tehran University of Medical Sciences, Tehran, Iran

2. Department of Surgery, Erfan Hospital, Tehran, Iran

\section{* Corresponding Author:}

Reza Parsaei, MD

Department of general surgery office, Imam Khomeini hospital complex, Keshavarz Boulevard, Tehran, Iran Telefax: + 9861192606

Email: rezparsaei@gmail.com

Received: 07 Mar. 2019

Accepted: 10 Jun. 2019
Please cite this paper as:

Toolabi K, Zamanian A, Parsaei R, Elyasinia F. An Unusual Cause of Upper Gastrointestinal Tract Obstruction. Middle East J Dig Dis 2019;11:177-178. doi: 10.15171/mejdd.2019.146.

A 79-year-old man presented to emergency department with the complaint of abdominal pain and vomiting since two days earlier. He had no history of abdominal pain or gastrointestinal disease. On physical examination, he was dehydrated and a significant distension was noted in the upper abdomen. Plain radiograph y showed a dilated stomach. Computed tomography a showed dilated stomach with a twist pattern (Figures 1,2).

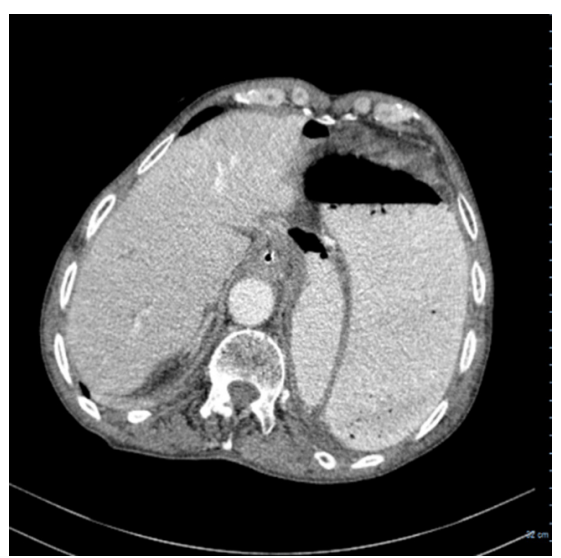

Fig.1: Computed tomography of abdomen (axial view).

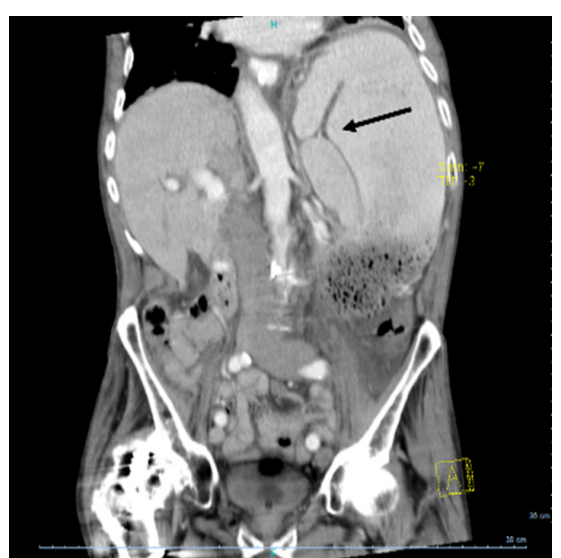

Fig.2: Computed tomography of abdomen (coronal view).

(c) (i) () 2019 The Author(s). This work is published by Middle East Journal of Digestive Diseaes as an open access (C) arg/licenses/by-nc/4.0/). Non-commercial uses of the work are permitted, provided the original work is properly cited.
ard 
What is your diagnosis?

\section{Answer:}

Stomach volvulus.

Intravenous fluids and electrolytes were administered and the patient was transferred to operating room. The stomach was untwisted. It was viable and no sign of ischemia was detected. We examined the diaphragm and hiatus thoroughly. No hiatal or diaphragmatic hernia was detected. The stomach was sutured to anterior abdominal wall. The patient's post-operative course was uneventful and he was discharged 3 days after surgery.

Gastric volvulus is a rare cause of gastric outlet obstruction, which is the result of stomach rotation around its axis. ${ }^{1,2}$ Affected patients usually present with abdominal or chest pain and vomiting. Proximal stomach becomes dilated and on physical examination, distension in the upper abdomen can be noted, suggesting gastric outlet obstruction. Since the stomach volvulus is quite rare, diagnosis is usually not suspected based on the history and physical exam.

Plain radiography shows a distended stomach. In the case of diagraphmatic or hiatal hernia, dilated stomach is seen in the chest. A particularly helpful characteristic of plain radiography is that in volvulus, stomach contour changes to a spherical shape. ${ }^{3}$ Computed tomography is helpful in diagnosis and shows dilated stomach twisted around its axis. ${ }^{2}$ In cases that imaging cannot lead to diagnosis, upper gastrointestinal endoscopy shows twisting of stomach, specific for stomach volvulus.

Management begins with fluid and electrolytes replacement and stomach decompression by nasogastric tube. Treatment of gastric volvulus usually requires surgery. Stomach is untwisted and if there is a predisposing anatomic defect like diagraphmatic or paraesophageal hernia, the defect should be repaired. ${ }^{3}$

If there is no anatomic defect, stomach is untwisted and is sutured to anterior wall of the abdomen. ${ }^{4}$ It is not necessary to fix stomach to abdominal wall if an anatomical defect has caused volvulus. ${ }^{4}$

Alternatively, endoscopic untwisting of stomach and fixing stomach with percutaneous endoscopic gastrostomy tube can be carried out in primary gastric volvulus. ${ }^{5}$

\section{CONFLICT OF INTEREST}

The authors declare no conflict of interest related to this work.

\section{REFERENCES}

1. Rashid F, Thangarajah T, Mulvey D, Larvin M, Iftikhar SY. A review article on gastric volvulus: a challenge to diagnosis and management. Int J Surg 2010;8:18-24. doi: 10.1016/j.ijsu.2009.11.002.

2. Shivanand G, Seema S, Srivastava DN, Pande GK, Sahni P, Prasad R, et al. Gastric volvulus: acute and chronic presentation. Clin Imaging 2003;27:265-8.

3. Oh SK, Han BK, Levin TL, Murphy R, Blitman NM, Ramos C. Gastric volvulus in children: the twists and turns of an unusual entity. Pediatr Radiol 2008;38:297-304. doi: 10.1007/s00247-007-0709-5.

4. Mangray H, Latchmanan NP, Govindasamy V, Ghimenton F. Grey's Ghimenton gastropexy: an anatomic makeup for management of gastric volvulus. J Am Coll Surg 2008;206:195-8. doi:10.1016/j.jamcollsurg.2007.05.012.

5. Baudet JS, Armengol-Miró JR, Medina C, Accarino AM, Vilaseca J, Malagelada JR. Percutaneous endoscopic gastrostomy as a treatment for chronic gastric volvulus. Endoscopy 1997;29:147-8. doi:10.1055/s-2007-1004106.

\section{ETHICAL APPROVAL}

There is nothing to be declared. 